\title{
Techno-Socio-Economic Dimensions of Specialized Home Gardens
}

\author{
C. Sreelakshmi ${ }^{1}$ and Allan Thomas ${ }^{2}$
}

\begin{abstract}
The paper on home gardens delineates the techno-socio-economic dimensions of specializations in home gardens involving a total of 90 respondents from Thiruvanthapuram district in Kerala that comprised 60 specialized home garden farmers and 30 Agricultural Officers. Commercial interest has transformed this subsistence production system, to a means of additional income generation system with the inclusion of various specializations such as aquaculture, floriculture, sericulture and animal husbandry thus making it unique, ever-evolving and dynamic system. Different techno-socio- economic dimensions would have contributed to specializations in home gardens and hence the study was imperative. The results revealed that 11 out of 27 dimensions were perceived to be important. The results also revealed that the relevancy pattern differed for both specialized home garden farmers and agricultural officers wherein a few dimensions perceived to be important by farmers were actually not $a$ concern for agricultural officers and vice versa.
\end{abstract}

Keywords : Specialized home gardens; Technology; Dimensions; Techno-socio- economic; Commercial, Profit; Kerala

\section{INTRODUCTION}

Specialized home gardens are a special type of agricultural production system around home, with or without extended garden with home garden primary structure inclusive of specializations like apiculture, sericulture, aquaculture etc. specializations are included with commercial interest. Thus it becomes visibly different from general traditional types of home garden system (Krishnan, 2013) overriding the concept of subsistence use. The idea of sustainability from a systemdynamics angle includes two main dimensions, i.e. ecological sustainability and social sustainability in the sense of maintaining ecological constancy and adjusting to social dynamics (Wiersum, 2004). Hence technology (McGraw, 1982) components are deliberately incorporated making home gardens more complex biophysically and an ever evolving dynamic system. Because of the complexities of technologies in specialized home gardens different institutional arrangements generate and disseminate technologies and hence understanding the techno-socio-economic dimensions as perceived by home garden farmers and extension personnel is imperative.

1. PG Scholar, and 2. Assistant Professor, Department of Agricultural Extension, College of Agriculture, Vellayani, Thiruvananthapuram, Kerala-695522. 


\section{METHODOLOGY}

'Ex-post-facto' research design was used for conducting this study. The study was conducted in the Thiruvanathapuram district comprising five Agro Ecological Units (AEU) where the specialized home garden systems are in vogue. It includes AEU-1, AEU-8, AEU9, AEU-12 and AEU-14.

A list of panchayats in each AEU's of study was prepared and panchayats with potentially active and operational home garden units were identified. From each AEU, one panchayat each was selected randomly in consultation with Agricultural Officers. From each panchayat 12 specialized home gardens were selected randomly, thus making a total of 60 specialized home gardens. Thirty Agricultural Officers were randomly selected as the respondents for the study by including all agricultural officers in the study area.

Based on the review of literature and detailed discussion with experts, a list of dimensions that appeared to characterize the specializations in home gardens were prepared and administered to the specialized home garden farmers and agricultural officers. The judges were requested to rate the relevancy of each dimension on a 3-point continuum ranging from most relevant to least relevant with the weightages of " 1 "' to " 3 " respectively. The dimensions falling above mean total were perceived to be important for the category of respondents and vice-versa. Ranking method was adopted to determine relevance of each dimension separately for respondents and agricultural officers. Dimensions perceived to be important based on the mean value were analyzed estimating over class rank and Venn diagram were plotted for each dimension indicating the dimensions perceived to be important by both agricultural officers and respondents. Similarly, relevance of each dimension was analyzed AEU wise based on mean total scores for each dimension and ranking method was adopted to determine the relevancy of major contributing dimension.

\section{FINDINGS AND DISCUSSION}

\section{Different Dimensions Related to Specialized Components in Home Garden Situations}

The distribution of dimensions perceived to be important by specialized home garden farmers and agricultural officers of specialized home gardens is presented in Table-1.

The results revealed the perceptions of farmers and agricultural officers as to which dimension is more important.

Under the economic dimensions for specialized homegardens as perceived by the specialized home garden farmers, regularity of returns (2.77) was perceived to be the most important dimension followed by the income generation potential (2.65), initial cost (2.63) and commercialization (2.62). For agricultural officers, the dimensions perceived to be important was regularity of returns (2.87), initial cost (2.70) and income generation potential (2.67). Commercialization was an important factor as perceived by the respondents since majority of the home garden farmers incorporate specializations for economic returns. Respondents perceived 
Techno-Socio-Economic Dimensions of Specialized Home Gardens

Table 1

Dimensions Perceived to be Important by Specialized Home Garden Farmers and Agricultural Officers

\section{Dimensions}

\section{Economic dimensions}

\begin{tabular}{|l|c|c|c|c|c|c|c|c|}
\hline 1.Initial cost & 158.00 & 2.63 & 3 & 3 & 81 & 2.70 & 2 & 2 \\
\hline $\begin{array}{l}\text { 2.Income generation } \\
\text { potential }\end{array}$ & 159.00 & 2.65 & 2 & 2 & 80 & 2.67 & 3 & 3 \\
\hline $\begin{array}{l}\text { 3.Employment generation } \\
\text { potential }\end{array}$ & 149.00 & 2.48 & 5 & 8 & 73 & 2.43 & 5 & 7 \\
\hline 4.Commercialisation & 157.00 & 2.62 & 4 & 4 & 72 & 2.40 & 6 & 8 \\
\hline 5.Regularity of returns & 166.00 & 2.77 & 1 & 1 & 86 & 2.87 & 1 & 1 \\
\hline 6. Rapidity of returns & 146.00 & 2.43 & 6 & 11 & 76 & 2.53 & 4 & 4 \\
\hline Total & 155.83 & 2.59 & & & 78 & 2.6 & & \\
\hline
\end{tabular}

\section{Technical Dimensions}

\begin{tabular}{|c|c|c|c|c|c|c|c|c|}
\hline 7.Physical compatability & 148.00 & 2.47 & 5 & 9 & 68 & 2.27 & 7 & 12 \\
\hline 8.Efficiency & 143.00 & 2.38 & 7 & 12 & 71 & 2.37 & 3 & 9 \\
\hline 9.Trialability & 150.00 & 2.50 & 3 & 8 & 68 & 2.27 & 6 & 13 \\
\hline 10.Complexity & 139.00 & 2.32 & 8 & 14 & 69 & 2.30 & 5 & 12 \\
\hline 11.Predictability & 146.00 & 2.43 & 6 & 11 & 73 & 2.43 & 2 & 7 \\
\hline 12. Flexibility & 154.00 & 2.57 & 2 & 6 & 75 & 2.50 & 1 & 5 \\
\hline 13.Viability & 149.00 & 2.48 & 4 & 8 & 68 & 2.27 & 6 & 12 \\
\hline 14.Desirability & 155.00 & 2.58 & 1 & 5 & 70 & 2.33 & 4 & 11 \\
\hline Total & 148.77 & 2.47 & & & 70.11 & 2.33 & & \\
\hline \multicolumn{9}{|l|}{ Environmental dimensions } \\
\hline 15.Energy saving potential & 112.00 & 1.87 & 3 & 15 & 70 & 2.33 & 2 & 11 \\
\hline $\begin{array}{l}\text { 16.Local Resource } \\
\text { Utilisation }\end{array}$ & 155.00 & 2.58 & 1 & 5 & 69 & 2.30 & 3 & 12 \\
\hline 17. Sustainability & 154.00 & 2.57 & 2 & 6 & 72 & 2.40 & 1 & 8 \\
\hline Total & 140.33 & 2.34 & & & 70.33 & 2.34 & & \\
\hline
\end{tabular}




\begin{tabular}{|c|c|c|c|c|c|c|c|c|}
\hline \multirow[t]{2}{*}{ Dimensions } & \multicolumn{4}{|c|}{$\begin{array}{l}\text { Specialized home garden farmers, } \\
\qquad n=60\end{array}$} & \multicolumn{4}{|c|}{ Agricultural Officers, $n=30$} \\
\hline & Total & $\begin{array}{l}\text { Mean } \\
\text { total }\end{array}$ & $\begin{array}{l}\text { Rank } \\
\text { over } \\
\text { class }\end{array}$ & $\begin{array}{l}\text { Rank } \\
\text { over } \\
\text { total }\end{array}$ & Total & $\begin{array}{c}\text { Mean } \\
\text { total }\end{array}$ & $\begin{array}{l}\text { Rank } \\
\text { over } \\
\text { class }\end{array}$ & $\begin{array}{c}\text { Rank } \\
\text { over } \\
\text { total }\end{array}$ \\
\hline \multicolumn{9}{|l|}{ Socio-cultural dimensions } \\
\hline 18.Social acceptability & 153.00 & 2.55 & 1 & 7 & 71 & 2.37 & 1 & 9 \\
\hline 19.Social approval & 108.00 & 1.80 & 2 & 16 & 67 & 2.23 & 2 & 14 \\
\hline Total & 130.5 & 2.17 & & & 69 & 2.3 & & \\
\hline \multicolumn{9}{|l|}{ Psychological dimensions } \\
\hline 20. Attitude & 150.00 & 2.50 & 1 & 8 & 72 & 2.40 & 2 & 8 \\
\hline $\begin{array}{l}\text { 21. Perceptions of } \\
\text { technology }\end{array}$ & 139.00 & 2.32 & 3 & 14 & 74 & 2.47 & 1 & 6 \\
\hline 22.Perceived social status & 142.00 & 2.37 & 2 & 13 & 63 & 2.10 & 3 & 15 \\
\hline Total & 143.66 & 2.39 & & & 69.67 & 2.32 & & \\
\hline \multicolumn{9}{|c|}{ Human Resource Dimensions } \\
\hline 23. Family labour & 143.00 & 2.38 & 4 & 12 & 62 & 2.07 & 3 & 16 \\
\hline 24. Hired labour & 148.00 & 2.47 & 1 & 9 & 61 & 2.03 & 4 & 17 \\
\hline $\begin{array}{l}\text { 25.Physical labour } \\
\text { requirement }\end{array}$ & 147.00 & 2.45 & 2 & 10 & 68 & 2.27 & 2 & 13 \\
\hline $\begin{array}{l}26 . \text { Skilled labour } \\
\text { requirement }\end{array}$ & 146.00 & 2.43 & 3 & 11 & 70 & 2.33 & 1 & 10 \\
\hline Total & 146.00 & 2.43 & & & 65.25 & 2.17 & & \\
\hline
\end{tabular}

income generation potential more than initial cost due to the fact that without continuous income generation the specialization will be vague and of no use. Farmers will be in a position to manage the specialized home garden to overcome initial cost.

In case of the technical dimensions, desirability (2.58) and availability of supplies (2.58) followed by flexibility (2.57) were important to the respondents. Flexibility (2.50), predictability (2.43) and efficiency (2.37) were considered important by the agricultural officers. Desirability and availability of supplies were considered important because unless there is resource availability one cannot continue farm activities. Flexibility in all aspects helps to mitigate risks and overcome crisis situation in a better manner especially in specialized home gardens. Complexity was perceived to be least technical dimension by both farmers as well as agricultural officers. It implies irrespective of complex nature of technology farmers tend to adopt it due to profit motive of the farmers. 
Under environmental dimensions, when local resource utilization (2.58) was perceived to be important by the specialized homegarden farmers, sustainability was the dimension perceived to be important by the Agricultural Officers. However, sustainability was a mutual concern for both Agricultural Officers and specialized home garden farmers. Optimum usage of available resources was considered important to the farmers for the sustenance of specializations in home gardens. Energy saving potential (2.33) was perceived to be important by agricultural officers since it can also reduce the hazards on the environment as well as helps to reduce the financial costs to the farmers.

Under Socio-cultural dimension, social acceptability was unequivocally considered important by both agricultural officers and specialized home garden farmers. Acceptability from the society in turn can help the farmers to generate additional economic benefits when the specialization becomes commercialized.

Attitude (2.50) was important to both the category of respondents while a perception of technology (2.47) was important to the agricultural officers under psychological dimensions. Technology plays a very pivotal role starting from the germination of specialization till marketing of its products and hence without positive attitude a farmer will not venture for specializations.

Under Human Resource Dimension, hired labour (2.47) and family labour requirement (2.38) was a concern expressed by both categories of respondents. Scarcity of labour was a major problem expressed by majority of both the category of respondents. The results clearly indicate that skilled labour was a pivotal factor in home gardens inclusion of specializations requiring complex technology. Hence skilled labour (2.33) was considered pertinent by the agricultural officers and specialized home garden farmers as well.

Six major dimensions namely economical dimension, technical dimension, environmental dimension, socio-cultural dimension, psychological dimension and human resource dimensions in total were given for rating to both specialized home garden farmers and agricultural officers so as to identify the most important dimension as perceived by both categories of respondents. The results of the same, based on the mean values as check for both farmers and agricultural officers were delineated and presented in Fig 1.

Fig 1 represents Venn diagram for each dimension. The Venn diagrams were plotted for emphasizing the common dimensions perceived to be most important by both categories of respondents. It is interesting to note that from Fig 11, the total of 11 dimensions were felt to be important by both category of respondents where in the dimensions were E5, E2 and E1 under economic dimension: T12, T14 and T15 under technical dimensions: Ev18 under environmental dimensions: SC 19 under socio-cultural dimensions: P1 under psychological dimensions and H R 26, H R 27 under human resource dimension. 
1. Economic dimension

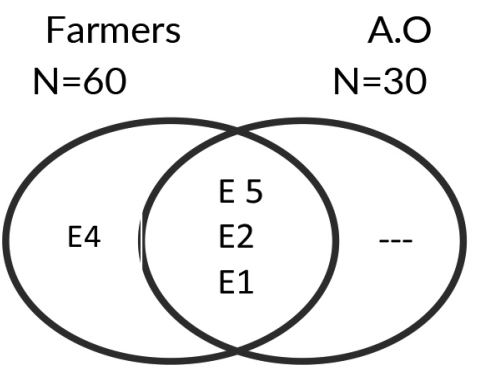

Mean (farmers): 2.59

Mean (A.O's) : 2.60
2. Technical dimension

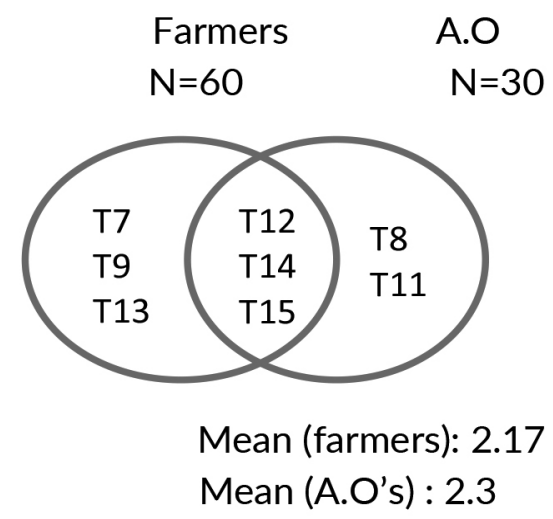

4. Socio-cultural dimension

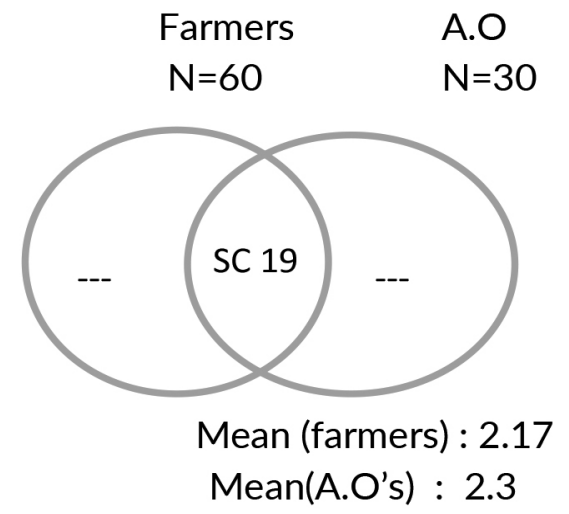

6. Human resource dimension

Farmers

A.O

$N=60 \quad N=30$

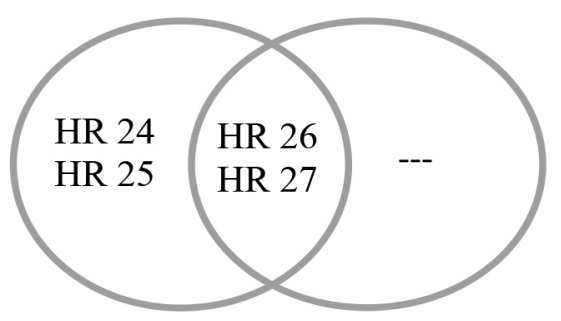

Mean (farmers) : 2.43

Mean (A.O's) : 2.17

Fig 1. Techno Socio -Economic Dimensions as Perceived to be Important by both the Categories of Respondents 
The common dimensions as perceived by both categories of respondents were identified considering the mean value of dimensions as check. Under economic dimension, the dimensions that were felt important by specialized home garden farmers and Agricultural Officers were regularity of returns (E5), income generation potential (E2) and initial cost (E1). Economic dimension are very important for any farmer because that determines the profitability of the specialized home garden. Moreover farmers venture into specialized components expecting profit. Rabin (2013) and Shepherd (2004) reported that profit is always a motivating factor for farmers to continue with farming. However the results also point to the fact under economic dimension, commercialization (E 4) that was felt important by farmers was not felt important by Agricultural Officers. Farmers might have perceived commercialization as an important dimension because they chose specialization for economic interest and to be not just a farmer but an agripreneur.

Flexibility (T12), desirability (T14) and availability of supplies (T15) under technical dimension were the dimensions that were felt important by both categories of respondents. However, physical compatability (T7), viability (T9) and trailability (T13) were the dimensions that were felt important by the specialized homegarden farmers but not by the Agricultural Officers. The farmers might have perceived that for a proper growth and sustenance of home garden, the inclusion of specializations should be compatible with the physical environment as well as to the existing non-specialized components. Viability and trailability could be referred to as twin pillars of any successful venture. When it comes to the specializations, requiring high risks and complex technology trailabilty of the same becomes more accentuated. However according to the Agricultural Officers, efficiency ( $T$ 8) and predictability ( $T$ 11) were pertinent. Unlike traditional home gardens the specialized home garden require high risks, thus having the ability to foresee the outcomes and track the growth of the venture might help to mitigate unexpected losses.

Under environmental dimensions, sustainability (Ev18) was perceived to be important to both Agricultural Officers and the specialized homegarden farmers. Sustainability which has become watchword of the policy makers is not a new concept in agriculture too. So it was unequivocally preferred by both categories of respondents. However the results also reflect that local resource utilization (Ev17) was felt important by the specializedhome garden farmers but not the agricultural officers. Tapping the available local resources may help in the easy mobility and effective resource utilisation particularly when value additions are taking place and helps in the sustainability of home gardens.

Social acceptability (SC19) was perceived to be important by both specialized home garden farmers as well as the agricultural officers. Ultimately any specialization that is incorporated symbolically should match with the culture and co- exist in the framework of the society.

Psychological dimensions that were important to both the categories of 
respondents include attitude (P1). Perceptions of technology (P2) were considered important by Agricultural Officers but not by the farmers. Agricultural Officers believed that farmers should have full faith in the agricultural extension system that includes the extension workers for positive adoption to take place. This will enable a productive perception on the technologies among the farming community which will ensure more trust between the farmer and extension system.

Human resource dimensions that were commonly perceived by both category of respondents include physical labour reqirement (HR26) and skilled labour (HR27). Specialized home gardens require additional skilled labour to carry out the operations in homegardens with complex technology. Family labour (HR 24) and hired labour (HR 25) were perceived important by the specialized home garden farmers. Labour shortage was a serious constraint expressed by the specialized home garden farmers. The government should initiate more schemes for developing the skill set of labourers through training so that skill set of labourers can be strengthened. This will enable both labourers as well as specialized home garden farmers to derive more profit.

\section{CONCLUSION}

The results revealed the perceptions of farmers and Agricultural Officers as to which dimension is more important. The result showed that relevancy pattern differed for both specialized home garden farmers and Agricultural Officers. Some dimensions perceived to be important by respondents were actually not a concern for Agricultural Officers and vice versa and that needs to be a focal point of discussion to the benefit of the specialized home garden farmers. Effective technology dissemination is the strength of the extension system in the state. Hence considering dimensions of the technology as perceived by the specialized home garden farmers and the agricultural officers, due thrust should be given to the above said dimensions with effective action from policy makers to enhance the welfare of the farmers and also the economic development of the state. All these can turn specialized home garden systems into a sustainable agricultural production system.

\section{REFERENCES}

Krishnan, R. (2013).Techno Socioeconomic characterization of specialized home gardens: A dominance diversity approach. Unpublished M.Sc (Ag) thesis, Kerala Agricultural University. Thrissur. $64 \mathrm{p}$.

McGraw, H. (1982). McGraw Encyclopedia of Science and Technology McGraw Hill Book Company, New York, 502 p.

Thomas, A \& Kumar, N.K. (2015). Technology needs assessment in the home garden systems, Journal of Extension Education, 27(4)

Wiersum, K.F. (2004). Forest gardens as an intermediate land-use system in the nature-culture continuum: characteristics and future potential. Agroforestry systems. 61: 123-134. 